\title{
Adsorptive Removal and Recovery of Aluminium (III), Iron (II), and Chromium (VI) onto a Low Cost Functionalized Phragmities Karka Waste
}

\author{
Shukraraj Regmi ${ }^{1}$, Kedar Nath Ghimire*1, Megh Raj Pokhrel ${ }^{1}$ and Deba Bahadur Khadka ${ }^{1}$ \\ ${ }^{1}$ Central Department of Chemistry \\ Tribhuvan University, Kritipur, Kathmandu, Nepal \\ *E-mail:knghimire@gmail.com
}

\begin{abstract}
Chemically modified adsorbent based on Phragmities stem has been investigated by treating with concentrated sulfuric acid at 2:1 weight/volume ratio. The maximum loading capacity for $\mathrm{Al}(\mathrm{III})$ and $\mathrm{Fe}(\mathrm{II})$ onto phosphorylated charred Phragmities waste PCPW adsorbent was found to be $148 \mathrm{mg} / \mathrm{g}$ and $200 \mathrm{mg} / \mathrm{g}$, while for Cr(VI) $200 \mathrm{mg} / \mathrm{g}$, respectively, at their optimal $\mathrm{pH}$. Similarly, it was $166.66 \mathrm{mg} / \mathrm{g}$ and $90.90 \mathrm{mg} / \mathrm{g}$ for $\mathrm{Al}(\mathrm{III})$ and $\mathrm{Fe}(\mathrm{II})$ onto the charred Phragmities waste CPW, respectively. The adsorption process followed the Freundlich isotherm and pseudo-second order kinetic models.. The desorption of the loaded metal ions recovery was found to be to the extent of $82 \%, 91 \%$ and $100 \%$ for $\mathrm{Al}(\mathrm{III}), \mathrm{Fe}(\mathrm{II})$ and $\mathrm{Cr}(\mathrm{VI})$, respectively.
\end{abstract}

Key words: Adsorption, Charred Phragmities waste, Phosphorylated charred Phragmities waste

\section{INTRODUCTION}

Heavy metals are high density toxic pollutants mainly include transitional metal, metalloids, lanthanides and actinide (Homagai et al. 2010), viz $\mathrm{Cr}(\mathrm{VI}), \mathrm{Cd}(\mathrm{II})$, $\mathrm{Pb}(\mathrm{II}), \mathrm{Fe}(\mathrm{III}), \mathrm{Fe}(\mathrm{II}), \mathrm{Al}(\mathrm{III}), \mathrm{Ni}(\mathrm{II}), \mathrm{Zn}(\mathrm{II}), \mathrm{Cu}(\mathrm{II})$ (Sharma and Forster 1994). Industrialization mainly concerns to the exploration of chemical industries cause them to release heavy metal into aquatic ecosystem. Electroplating, leather tanning, cement, mining, dyeing, fertilizer and photography industries contributes an important role to dispose the heavy metals to the environment. Heavy metals are non biodegradable and may cause health problem to animal, plants and human being. .Hexavalent chromium is carcinogenic, may cause liver damage, pulmonary congestion and skin irritation resulting in ulcer formation (Chand et al. 1994).

The tolerance limit for $\mathrm{Cr}(\mathrm{VI})$ for discharge into inland surface waters is $0.1 \mathrm{mgL}^{-1}$ and in potable water is 0.05 $\mathrm{mg} \mathrm{L}^{-1}$. But its concentration in industrial waste water ranges from $0.5-270 \mathrm{mg} \mathrm{L}^{-1}$. Hexavalent chromium, $\mathrm{Cr}(\mathrm{VI})$ exists in the aqueous solution as oxyanions such as chromate $\left(\mathrm{CrO}_{4}^{2-}\right)$, dichromate $\left(\mathrm{Cr}_{2} \mathrm{O}_{7}{ }^{2-}\right),\left(\mathrm{HCrO}_{4}^{-}\right)$ and $\left(\mathrm{HCr}_{2} \mathrm{O}_{7}^{-}\right)$form (Mohan et al. 2006). Trivalent aluminum is non essential to the plants and animals. Excess solubility of $\mathrm{Al}(\mathrm{III})$ in water cause the destruction on of bone, lungs, spleen liver, and brain. It also causes alzehimers, clinically characterized by gradual loss of cognitive function. Chromium ingestion may cause dentalcaries, hepatic and renal dysfunction, neuromuscular disorders, Osteomalacia and blood cancer (Mohan et al. 2006). UN food and agricultural organization recommended its maximum level for irrigation water to $5 \mathrm{mg} / \mathrm{L}$. In ground water, its concentration should be less than $0.1 \mu \mathrm{g} / \mathrm{L}$ (Benefield $e t$ al.2007). Iron is also toxic if present in excess, which may cause anorexia, oliguria, hypothermia, diphasic shock and metabolic acidosis and even death. In addition to these, patients experiences vascular congestion of the gastrointestinal tract and liver toxicity via lipid peroxidation and destruction of hepatic mitochondria. There are different methods of treatment of heavy metal contaminated water. They are chemical precipitation, lime coagulation, ion-exchange, reverse osmosis, solvent extraction, reduction, electrodialysis, evaporation, electrochemical precipitation and so forth. However, these methods are not widely acceptable due to high capital and operational costs and problem in disposal of residual metal sludge (Mohan et al. 2006). Biosorption is an effective and versatile method for removing of these heavy metals contaminated effluents. There are a number of biosorbents which have been investigated for the removal of different metals from aqueous solution (Ghimire et al. 2002). The chemically modified adsorbent is commonly used for removing $\mathrm{Al}(\mathrm{III}), \mathrm{Fe}(\mathrm{II})$ and $\mathrm{Cr}(\mathrm{VI})$ because of its effective 
adsorption capacity in trace level at low cost (Homagai et al. 2010). These chemically modified polymer of cellulose which are prepared from agriculture waste contain high percentage of carbon and have fairly high adsorption capacity for heavy metals including $\mathrm{Al}(\mathrm{III})$, $\mathrm{Fe}(\mathrm{II}), \mathrm{Cr}(\mathrm{VI})$. A great interest has been focused to understand the mechanism of adsorption of these metals in adsorbent prepared from agriculture waste.

The carbon prepared from agriculture waste can be activated by various method like chemical modification, steam activation, thermal activation etc. By means of such activation, the effective surface area of carbon increases and surface of the adsorbent gets modified due to formation of different functional groups (Mohan et al. 2006). In Nepal lots of biomaterial like, Phragmities stem, sugarcane bagasses, rice husk, maize barn, apple waste, orange waste and banana bark are easily available as waste material. Phragmities stem is one of the very popular in making roof and bar in agricultural farm and the waste produced is abundantly found in mountain and Terai region of Nepal, it is burnt as a less efficient fuel causing air pollution mainly in October season. Therefore, it is quite suitable to use as an adsorbent rather than wasting. In this research work, Phragmities stem collected from periphery of Tribhuvan University, Kritipur, Kathmandu has been explored to convert into cost effective environment friendly bioadsorbent for the removal of $\mathrm{Al}(\mathrm{III}), \mathrm{Fe}(\mathrm{II}), \mathrm{Cr}(\mathrm{VI})$ from aqueous solution.

\section{MATERIALS AND METHODS}

\section{Chemicals}

All chemicals, potassium dichromate, phosphoric acid, dimethyl formamide, 1,5 diphenylcarbazide (DPCI) , ferrous ammonium sulfate, potash alum , sulfuric acid, propanol employed were of reagent grade. Distilled water was used for the preparation of all solutions.

\section{Preparation of bioadsorbent}

Phragmities stem were collected from the periphery of Tribhuvan University. It was washed with distilled water and dried in sunlight and finally dried in oven at $70^{\circ} \mathrm{C}$ for $2 \mathrm{~h}$. It was cut into small pieces and grounded into powder and sieved to pass through $250 \mu \mathrm{m}$ mesh size. The material was equilibrated in concentrated $\mathrm{H}_{2} \mathrm{SO}_{4}$ at 2:1 weight/volume ratio and allowed to soak for 24 hours at room temperature. The samples were then washed with distilled water till neutral and dried at $80^{\circ} \mathrm{C}$ for 3 hours (Ghimire et al. 2008).

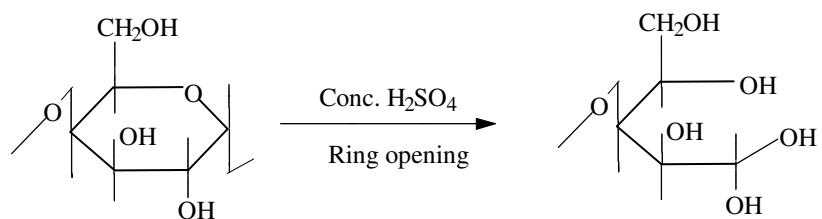

Fig. 1. Plausible reaction scheme for charring with sulphuric acid (Humagain et al. 2010).

\section{Phosphorylation of charred adsorbents \& reaction} scheme

An amount of $20 \mathrm{~g}$ dried CPW adsorbent was soaked in $250 \mathrm{~mL}$ of DMF for overnight in $500 \mathrm{~mL}$ three naked flask. The flask was equipped with magnetic stirrer. Then $30 \mathrm{~g}$ of urea was added into the flask with constant stirring followed by the addition of $40 \mathrm{~mL}$ of $\mathrm{H}_{3} \mathrm{PO}_{4}$ drop wise with constant stirring. The mixture was refluxed for 3 hours at a temperature of $150{ }^{\circ} \mathrm{C}$ on paraffin bath. After cooling to room temperature, it was washed with $500 \mathrm{~mL}$ of $70 \%$ propanol followed by water till neutrality was obtained. The solid product was dried in sunlight and then in oven for 24 hours at $60^{\circ} \mathrm{C}$. Thus obtained dried bioadsorbent was termed as PCPW. The phosphorylation reaction can be expressed schematically (Ghimire et al. 2002) as:

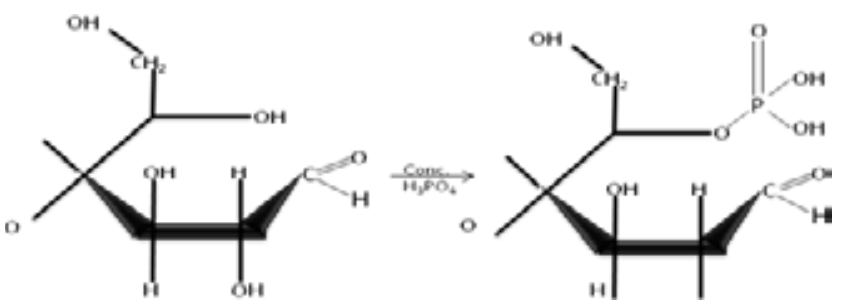

Fig. 2. Plausible reaction scheme for phosphorylation of charred adsorbent

\section{Spectrophotometric determination of metal ions}

Spectrophotomertric determination of aluminum ion was carried out using erichrome cyanine $\mathrm{R}$ as an complexing agent. With this reagent, dilute $\mathrm{Al}$ solution buffered to a $\mathrm{pH}$ of 6 produced red to pink color complexes that exhibit maximum absorption at $530 \mathrm{~nm}$. The intensity of the developed color is influenced by the aluminium concentration, reaction time, temperature, $\mathrm{pH}$, alkalinity and concentration of the other ions. The minimum and maximum concentration range detectable by this method in the absence of fluorides and complex phosphate is approximately 6-400 ppb. A pure reagent should be brick red in color, which fed to a pale yellow color in about two weeks. It appears that the form of the dye which reacts with $\mathrm{Al}$ ion is the strongly color one. Hence, it is most important for the optimization of the 
reagent that should be added in complex formation. Sensitivity and detection limit for the atomic absorption spectroscopy (AAS) methods, the ICP methods and the phenanthroline colorimetric procedure are almost similar and generally adequate for the analysis of natural and treated water (Mendham et al. 2003).

Thiocynate, dipyridine, tripyridine and 1,10 phenanthroline are important indicators for the spectrophotometric determination of iron. The method consisting of red complex that forms between $\mathrm{Fe}(\mathrm{II})$ and 1,10 phenanthroline seemed to be more practical and sensitive. The orange red phenanthroline complex $\left(\mathrm{C}_{12} \mathrm{H}_{8} \mathrm{~N}_{2}\right) \mathrm{Fe}^{2+}$ can be formed quantitatively in the $\mathrm{pH}$ range 2 to 9 with the suitable reagent concentration.

$$
\mathrm{Fe}^{2+}+3 \text { phen } \rightarrow \mathrm{Fe}(\text { phen })_{3}{ }^{2+}
$$

The molar extinction coefficient of the complex $\left(\mathrm{C}_{12} \mathrm{H}_{8} \mathrm{~N}_{2}\right) \mathrm{Fe}^{2+}$, is 11,100 at $508 \mathrm{~nm}$. The intensity of the color is independent of $\mathrm{pH}$ in the range of 3 to 9 . The complex was very stable and the color intensity did not change appreciably over long period of time. Color standards were stable for at least 6 months.

The iron must be in ferrous state, and hence a reducing agent is added before the color is developed. Hydroxylamine hydrochloride can be used to reduce ferric ion to ferrous form.

$2 \mathrm{Fe}^{3+}+2 \mathrm{NH}_{2} \mathrm{OH}+20 \mathrm{H}^{-} \rightarrow 2 \mathrm{Fe}^{2+}+\mathrm{N}_{2}+4 \mathrm{H}_{2} \mathrm{O}$.

The $\mathrm{pH}$ was adjusted to 4.5 by using the acetate buffer. A more sensitive method for the determination of chromium(VI) is diphenylcarbazide indicator (DPCI) method, in which $\mathrm{Cr}$ (VI) forms a pink colored complex with 1,5-diphenylcarbazide in acidic medium and can be spectrophotometricaly analyzed ((Mendham et al. 2003).

\section{Adsorption tests}

Batch $\mathrm{pH}$ studies were performed by shaking $25 \mathrm{~mL}$ of $25 \mathrm{mg} / \mathrm{L}$ of $\mathrm{Al}(\mathrm{III}), \mathrm{Fe}(\mathrm{II})$ and $\mathrm{Cr}(\mathrm{VI})$ solutions with 25 $\mathrm{mg}$ of adsorbents in a mechanical shaker at room temperature for 24 hours over a wide range of initial $\mathrm{pH}$ values from 1.0 to 6.0. The concentration of all metal ions before and after adsorption was determined by suitable indicator using WPA Linton Cambridge UK, type S104 No 385 Spectrophotometer. Adsorption kinetic studies were carried out by shaking $25 \mathrm{mg}$ of adsorbent with solution of $\mathrm{Al}$ (III), $\mathrm{Fe}(\mathrm{II})$ and $\mathrm{Cr}(\mathrm{VI})$ in $50 \mathrm{~mL}$ conical flask at room temperature. The removal kinetics of $\mathrm{Al}(\mathrm{III}), \mathrm{Fe}(\mathrm{II})$ and $\mathrm{Cr}(\mathrm{VI})$ was investigated by drawing the samples after desired contact time and the filtrate was analyzed for the residual metal ion concentration.
Adsorption isotherm studies were conducted by varying the initial concentration of $\mathrm{Al}(\mathrm{III}), \mathrm{Fe}(\mathrm{II})$ and $\mathrm{Cr}(\mathrm{VI})$ from $10 \mathrm{mg} / \mathrm{L}$ to $500 \mathrm{mg} / \mathrm{L}$. $25 \mathrm{~mL}$ of metal ion solution having different concentrations were shaken using mechanical shaker for 24 hours with $25 \mathrm{mg}$ of adsorbent for both CPW and PCPW at optimum $\mathrm{pH}$ respectively. The remaining metal ion concentration was determined after filtering the reaction mixture by using WPA spectrophotometer.

From the metal ion concentration measured before and after adsorption, amount of metal ion adsorbed onto adsorbent is determined by using following equation (1).

$$
q_{t}=\frac{\mathrm{C}_{\mathrm{i}}-\mathrm{C}_{\mathrm{e}}}{\mathrm{W}} \times \mathrm{V}
$$

Where, $C_{i}$ and $C_{e}$ are initial \& equilibrium metal ion concentrations in $\mathrm{mg} / \mathrm{L}$, respectively. $\mathrm{q}_{\mathrm{t}}$ is the amount of metal ion adsorbed at time ' $\mathrm{t}$ ' in $\mathrm{mg} / \mathrm{g}$. $\mathrm{V}$ is the volume of metal ion solution in $\mathrm{L}$. W is the weight of adsorbent in $\mathrm{g}$.

Metal ion removal percentage is calculated by using the following equation (2).

$$
A(\%)=\frac{\mathrm{C}_{\mathrm{i}}-\mathrm{C}_{\mathrm{e}}}{\mathrm{C}_{\mathrm{i}}} \times 100
$$

This is the ratio of decrease in metal ion concentration before and after adsorption to the initial concentration.

\section{RESULTS AND DISCUSSION}

\section{Effect of pH}

The maximum adsorption of $\mathrm{Al}(\mathrm{III})$ was found at $\mathrm{pH}$, afterwards the adsorption of $\mathrm{Al}(\mathrm{III})$ ion decreases due to the rapid precipitation of $\mathrm{Al}(\mathrm{OH})_{3}$. It is believed that most of the metal ions including $\mathrm{Al}$ (III) is removed from aquous solution by cation exchange mechanism because at higher $\mathrm{pH}$ binding sites of the adsorbent start deprotonating and the metal ion uptake become difficult (Sud et al. 2008).

The $\mathrm{pH}$ of the aqueous solution is an important parameter in the removal of metal by adsorption. The metal removal capacity generally increases with the increase in $\mathrm{pH}$. Fig. 3 shows that the \% adsorption of $\mathrm{Fe}(\mathrm{II})$ increases up to optimal $\mathrm{pH} 2.7$ and then decreased. It can be observed that \% adsorption of Fe(II) is greater for PCPW than CPW, respectively.

The adsorption of $\mathrm{Cr}(\mathrm{VI})$ onto $\mathrm{CPW}$ decreases from $100 \%$ to $26.66 \%$ when the $\mathrm{pH}$ of the solution increased from 1 to 6 as shown in Fig. 3. It is obvious that $\mathrm{pH}$ determines the extent of the $\mathrm{Cr}(\mathrm{VI})$ removal as well as providing a favorable removal adsorbent surface 
charge for the adsorption to occur. At low $\mathrm{pH}$, chromium exists as $\mathrm{HCrO}_{4}^{-}$. From the batch $\mathrm{pH}$ studies it was found that the adsorption of $\mathrm{Cr}(\mathrm{VI})$ was found to be effective at $\mathrm{pH} 1$ and 2 (Lal et al. 2010).

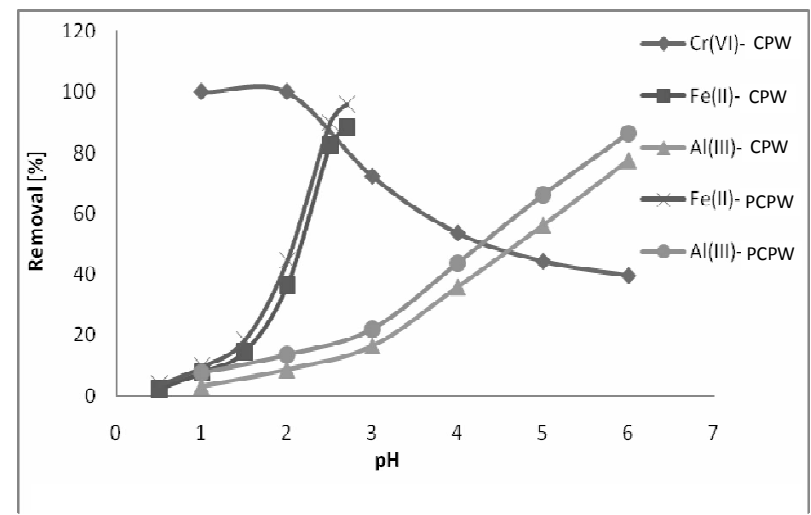

Fig. 3. Effect of pH in the removal of $\mathrm{Al}(\mathrm{III}), \mathrm{Fe}(\mathrm{II})$ and $\mathrm{Cr}(\mathrm{VI})$ as a function of $\mathrm{pH}$

\section{Effect of contact time}

Fig. 4 shows the adsorption of $\mathrm{Al}(\mathrm{III}), \mathrm{Fe}(\mathrm{II})$ and $\mathrm{Cr}(\mathrm{VI})$ onto CPW and PCPW from 5 minutes to infinite time. The optimum time for the adsorption of $\mathrm{Fe}(\mathrm{II})$ onto CPW and PCPW was 3 hours. From this data, it can be concluded that PCPW is better adsorbent than others as it brings equilibrium quickly.

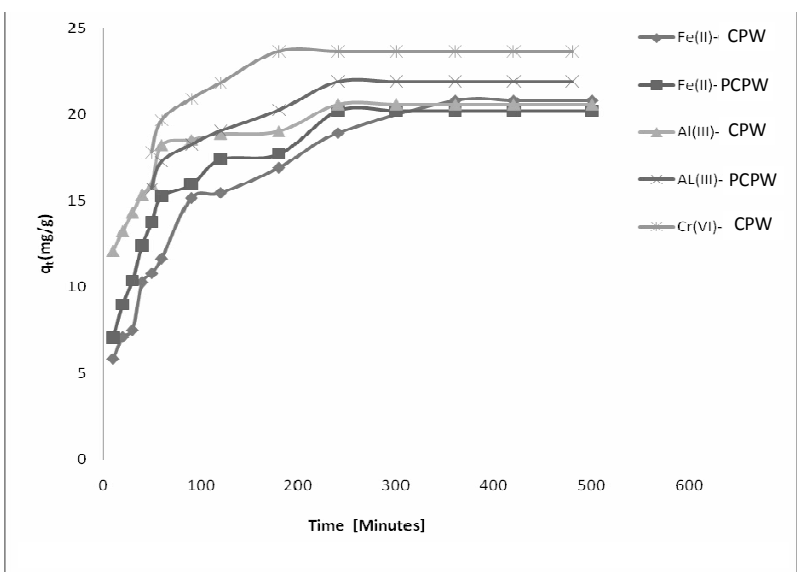

Fig. 4. Effect of contact time on the removal of $\mathrm{Al}$ (III), $\mathrm{Fe}(\mathrm{II})$ and $\mathrm{Cr}$ (VI) from aqueous solution

\section{Adsorption Isotherms}

The experimental data for the adsorptive removal of $\mathrm{Al}(\mathrm{III}), \mathrm{Fe}(\mathrm{II})$ and $\mathrm{Cr}(\mathrm{VI})$ from aqueous solution was analyzed by using Langmuir and Freundlich isotherm models. The respective metal ion adsorption isotherms of CPW and PCPW are shown in Figure 5 to Figure 9.

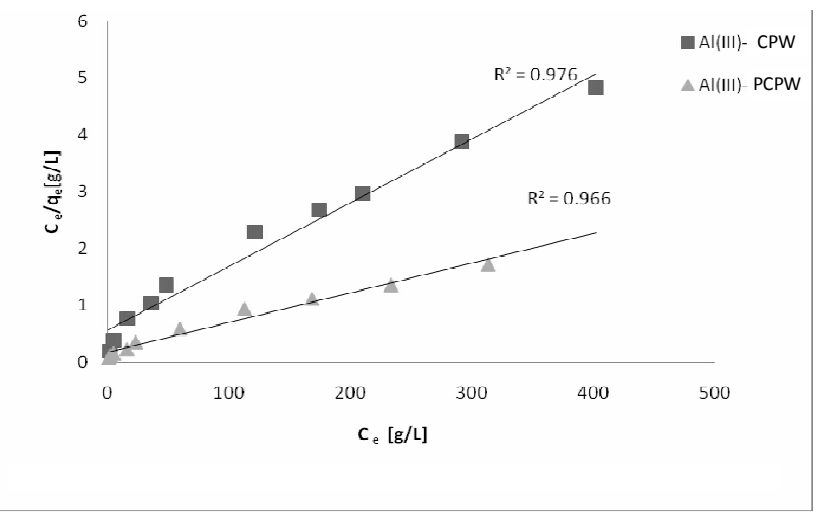

Fig. 5. Langmuir adsorption isotherm for the adsorption of $\mathrm{Al}(\mathrm{III})$ on to CPW and PCPW

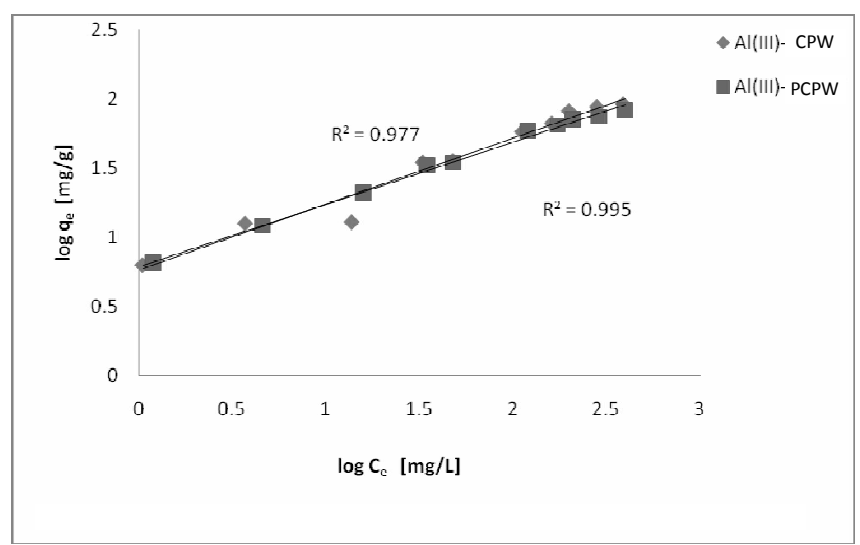

Fig. 6. Freundlich adsorption isotherm for the adsorption of $\mathrm{Al}(\mathrm{III})$ on to CPW and PCPW

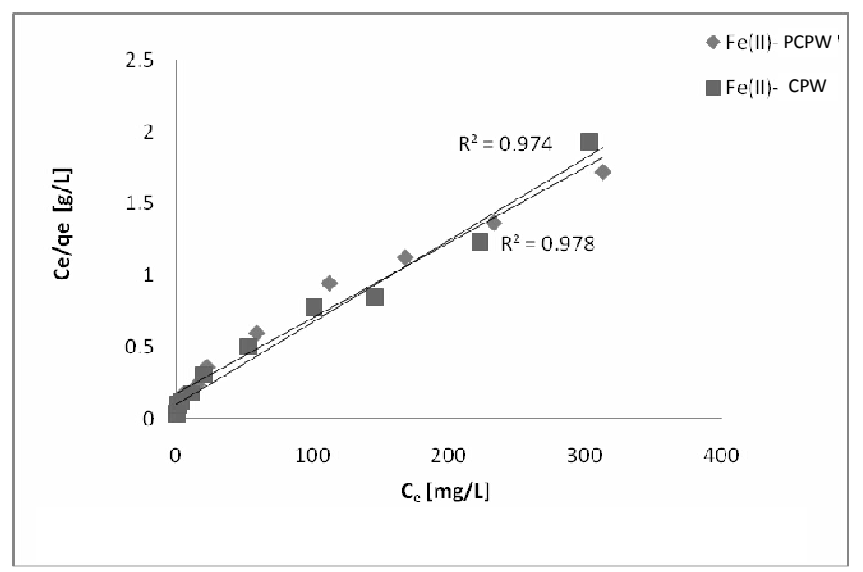

Fig. 7. Langmuir adsorption isotherm for the adsorption of $\mathrm{Fe}(\mathrm{II})$ on to CPW and PCPW 


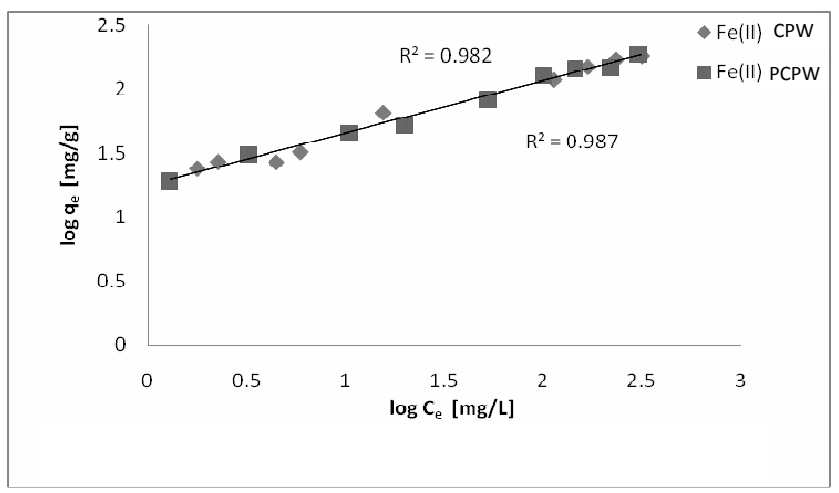

Fig. 8. Freundlich adsorption isotherm for the adsorption of $\mathrm{Fe}(\mathrm{II})$ on to CPW and PCPW

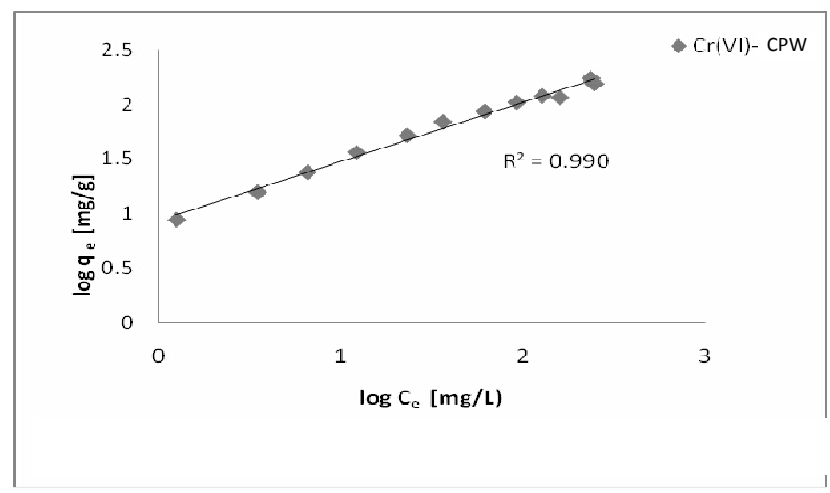

Fig. 9. Freundlich adsorption isotherm for the adsorption of $\operatorname{Cr}(\mathrm{VI})$ on to CPW and PCPW

Table 1. Langmuir and Freundlich adsorption parameters for the adsorption of Al(III) onto CPW \& PCPW.

\begin{tabular}{|c|c|c|c|c|c|c|c|}
\hline \multirow{2}{*}{ Adsorbent } & \multirow{2}{*}{$\begin{array}{c}\mathrm{q}_{\mathrm{m}} \text { exp. } \\
(\mathrm{mg} / \mathrm{g})\end{array}$} & \multicolumn{3}{|c|}{ Langmuir Isotherm } & \multicolumn{3}{c|}{ Freundlich Isotheirm } \\
\cline { 3 - 8 } & & $\mathrm{q}_{\mathrm{m}}(\mathrm{mg} / \mathrm{g})$ & $\mathrm{b}(\mathrm{L} / \mathrm{mg})$ & $\mathrm{R}^{2}$ & $\mathrm{~K}(\mathrm{mg} / \mathrm{g})$ & $1 / \mathrm{n}$ & $\mathrm{R}^{2}$ \\
\hline $\mathrm{CPW}$ & 82.00 & 90.90 & 0.019 & 0.976 & 5.78 & 0.475 & 0.977 \\
\hline PCPW & 94.00 & 142.85 & 0.017 & 0.966 & 6.15 & 0.450 & 0.995 \\
\hline
\end{tabular}

Table 2. Langmuir and Freundlich parameters for the adsorption of Fe(II) onto CNPW \& PCPW.

\begin{tabular}{|c|c|c|c|c|c|c|c|}
\hline \multirow[t]{2}{*}{ Adsorbent } & \multirow{2}{*}{$\begin{array}{c}\mathrm{q}_{\mathrm{m}} \text { exp. } \\
(\mathrm{mg} / \mathrm{g})\end{array}$} & \multicolumn{3}{|c|}{ Languir Isotherm } & \multicolumn{3}{|c|}{ Freundlich Isotherm } \\
\hline & & $\mathrm{q}_{\mathrm{m}}(\mathrm{mg} / \mathrm{g})$ & $\mathrm{b}(\mathrm{L} / \mathrm{mg})$ & $\mathrm{R}^{2}$ & $\mathrm{~K}(\mathrm{mg} / \mathrm{g})$ & $1 / \mathrm{n}$ & $\mathrm{R}^{2}$ \\
\hline CPW & 165.00 & 166.66 & 0.028 & 0.974 & 10.59 & 0.527 & 0.982 \\
\hline PCPW & 190.00 & 200 & 0.039 & 0.978 & 13.96 & 0.490 & 0.987 \\
\hline
\end{tabular}

Table 3. Languir and Freundlich parameters for the adsorption of $\operatorname{Cr}(\mathrm{VI})$ onto CPW \& PCPW.

\begin{tabular}{|c|c|c|c|c|c|c|c|}
\hline \multirow{2}{*}{ Adsorbent } & \multirow{2}{*}{$\begin{array}{c}\mathrm{q}_{\mathrm{m}} \text { exp. } \\
(\mathrm{mg} / \mathrm{g})\end{array}$} & \multicolumn{3}{|c|}{ Langmuir isotherm } & \multicolumn{3}{c|}{ Freundlich isotheirm } \\
\cline { 3 - 8 } & & $\mathrm{q}_{\mathrm{m}}(\mathrm{mg} / \mathrm{g})$ & $\mathrm{b}(\mathrm{L} / \mathrm{mg})$ & $\mathrm{R}^{2}$ & $\mathrm{~K}(\mathrm{mg} / \mathrm{g})$ & $1 / \mathrm{n}$ & $\mathrm{R}^{2}$ \\
\hline $\mathrm{CPW}$ & 176.00 & 200 & 0.018 & 0.968 & 7.74 & 0.565 & 0.990 \\
\hline
\end{tabular}

Langmuir and Freundlich parameters shown in Table 1 to Table 3 were determined from the slope and intercept of their respective plots. The values of Langmuir equilibrium parameters which lie between 0 and 1 indicated that equilibrium data fits well with Langmuir adsorption isotherm. The values of $1 / \mathrm{n}$ lie between 0 and 1 indicated that adsorption process is favorable.

Correlation coefficient values for Freundlich isotherms were found to be greater than that of Langmuir isotherms indicating that the adsorption process is better defined by the Freundlich adsorption isotherm model than by the Langmuir, which indicated the heterogenous distribution of active sites on the surface of adsorbent.. The higher values of $\mathrm{q}_{\mathrm{m}}$ (both experimental and calculated from plots) for PCPW indicated that PCPW has higher adsorption capacity for $\mathrm{Al}(\mathrm{III}), \mathrm{Fe}(\mathrm{II})$ and $\mathrm{Cr}(\mathrm{VI})$ than CPW.

\section{Kinetics}

Kinetics studies for the adsorption of $\mathrm{Al}(\mathrm{III}), \mathrm{Fe}(\mathrm{II})$ and $\mathrm{Cr}(\mathrm{VI})$ onto $\mathrm{CPW}$ and PCPW were performed using pseudo-first order, pseudo-second order and second order models and the plots for pseudo-second order kinetic model are presented in Figure 10 to Figure 12. 


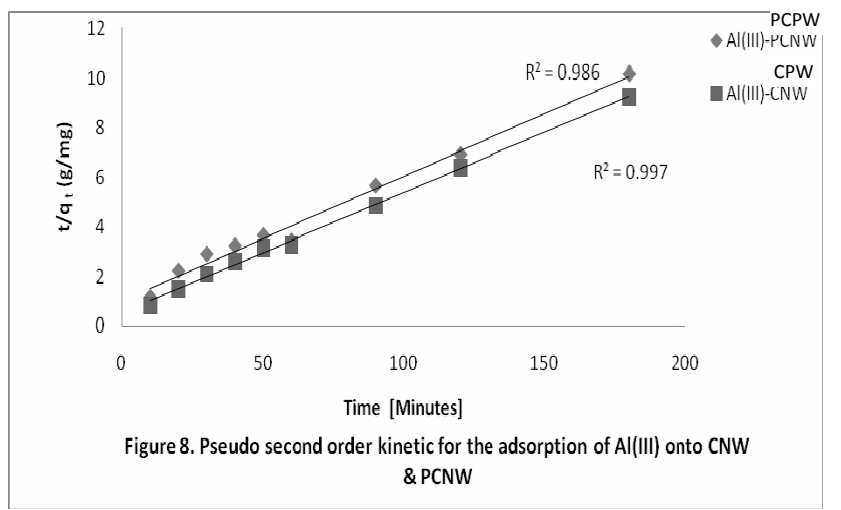

Fig. 10. Pseudo second order kinetic plot for the adsorption of $\mathrm{Al}(\mathrm{III})$ on to CPW and PCPW

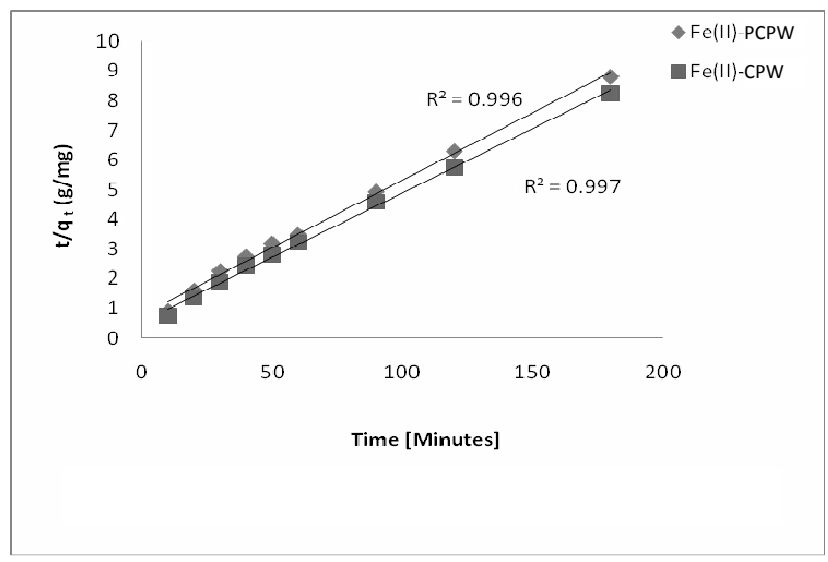

Fig. 11. Pseudo second order kinetic plot the adsorption of Fe(II) on to CPW and PCPW

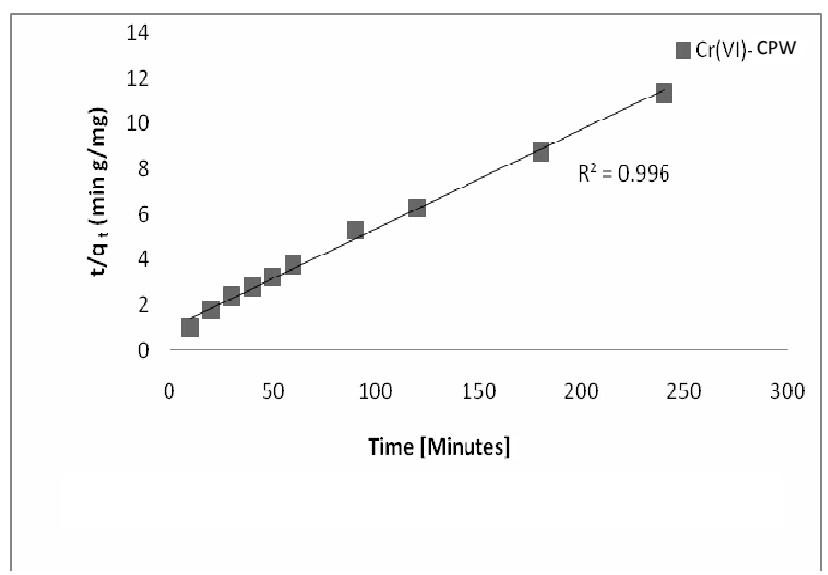

Fig. 12. Pseudo second order kinetic plot the adsorption of Cr(VI) on to CPW and PCPW

From the kinetic plots of adsorption of $\mathrm{Al}(\mathrm{III}), \mathrm{Fe}(\mathrm{II})$ and $\mathrm{Cr}(\mathrm{VI})$ onto $\mathrm{CPW}$ and PCPW it can be observed that the correlation coefficient $\left(\mathrm{R}^{2}\right)$ values for the pseudo second order were found to be higher than that of pseudo-first order and second order kinetic models.
The correlation coefficient $\left(\mathrm{R}^{2}\right)$ values of $\mathrm{Al}$ (III) for pseudo second order kinetic plots for CPW and PCPW were found to be 0.997 and 0.986 which are greater than the values for pseudo first order kinetic plots (0.884 and 0.898, not shown in Figure). Similarly, the correlation coefficient $\left(\mathrm{R}^{2}\right)$ values for $\mathrm{Fe}(\mathrm{II})$ for $\mathrm{CPW}$ and PCPW were found to be 0.964 and 0.969 , while for $\mathrm{Cr}(\mathrm{VI})$ for $\mathrm{CPW}$ it was found to be 0.982 . The overall correlation coefficient values for all metals regarding second order kinetics was not remarkable.

The correlation coefficient values for pseudo-second order kinetic plot for $\mathrm{Al}(\mathrm{III})$ and $\mathrm{Fe}(\mathrm{II})$ onto $\mathrm{CPW}$ and PCPW were found to be $0.997,0.986$ and $0.997,0.996$, respectivly, while for $\mathrm{Cr}(\mathrm{VI})$ onto $\mathrm{CPW}$ it was 0.996. Thus the experimental results revealed that the adsorption process followed pseudo second order kinetics model with higher correlation coefficient value.

\section{Desorption study and metal recovery}

The efficiency of the absorbents was analyzed through the series of adsorption/desorption experiments. In this study, efficiency of the adsorbent was analysed by conducting desorption experiment up to three cycles and the percentage of metal ion recovery was analyzed. The data obtained showed that the adsorbent is efficient and can be used repeatedly for several times.

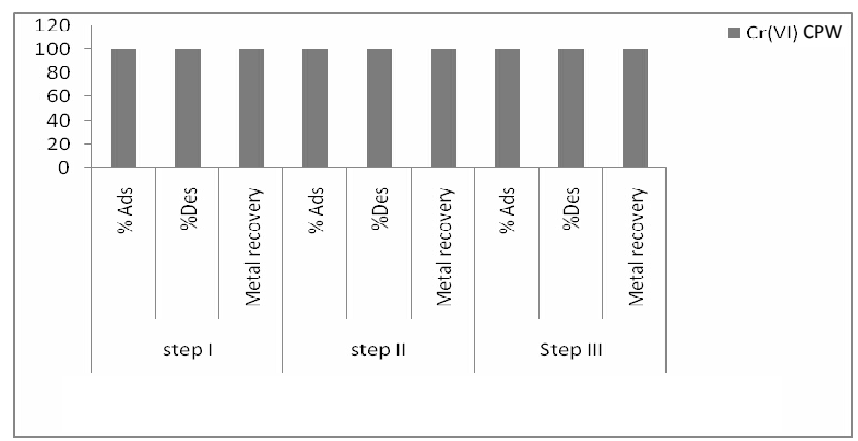

Fig. 13. Maximum adsorption, desorption and recovery of Cr(VI) onto CPW

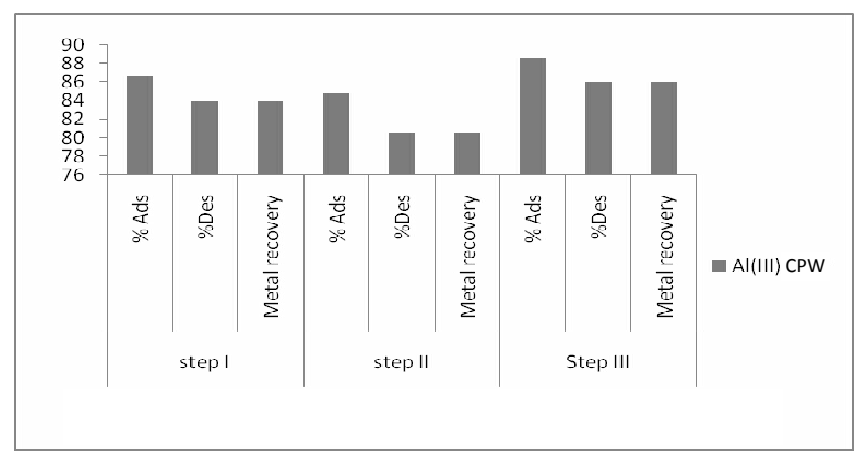

Fig. 14. Maximum adsorption, desorption and recovery of AI(III) onto CPW 


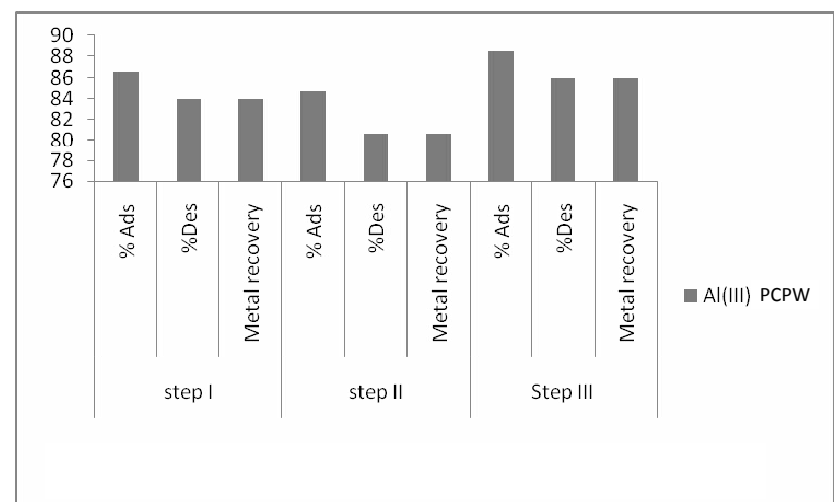

Fig. 15. Maximum adsorption, desorption and recovery of Al(III) onto PCPW

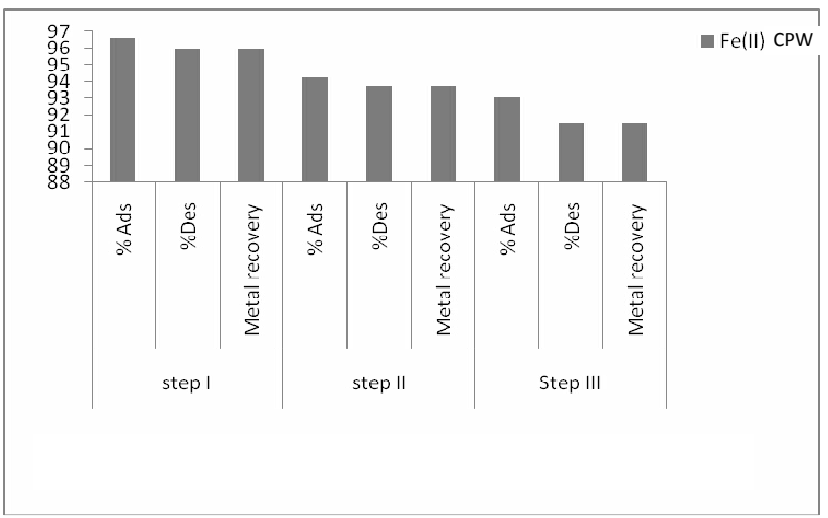

Fig. 16. Maximum adsorption, desorption and recovery of Fe(II) onto CPW

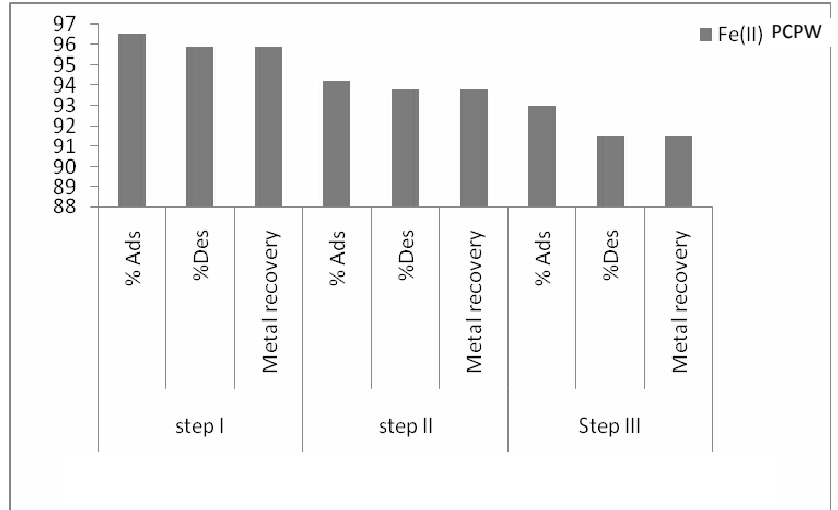

Fig. 17. Maximum adsorption, desorption and recovery of $\mathrm{Fe}($ II) onto CPW

\section{Plausible adsorption mechanism}

After charring, the polymeric cellulose of Phragmities become chemically modified which provided the suitable site for the maximum possible adsorption of the metal. After phosphorylation, adsorbent consists of phosphoric group, which drastically alter the adsorption mechanism by many fold accordingly with cation exchange mechanism. The metal cations $\mathrm{Al}$ (III) and $\mathrm{Fe}(\mathrm{II})$ are considered to be adsorbed on the phosphoric group, while such adsorption of $\mathrm{Cr}(\mathrm{VI})$ onto phosphate group is not possible, due to the repulsion of same charge ions. Hence, adsorption takes place through complexation with polyphenolic group (Ghimire et al. 2002)

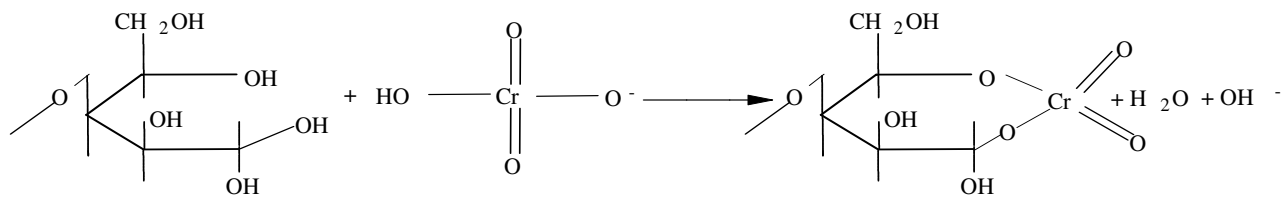

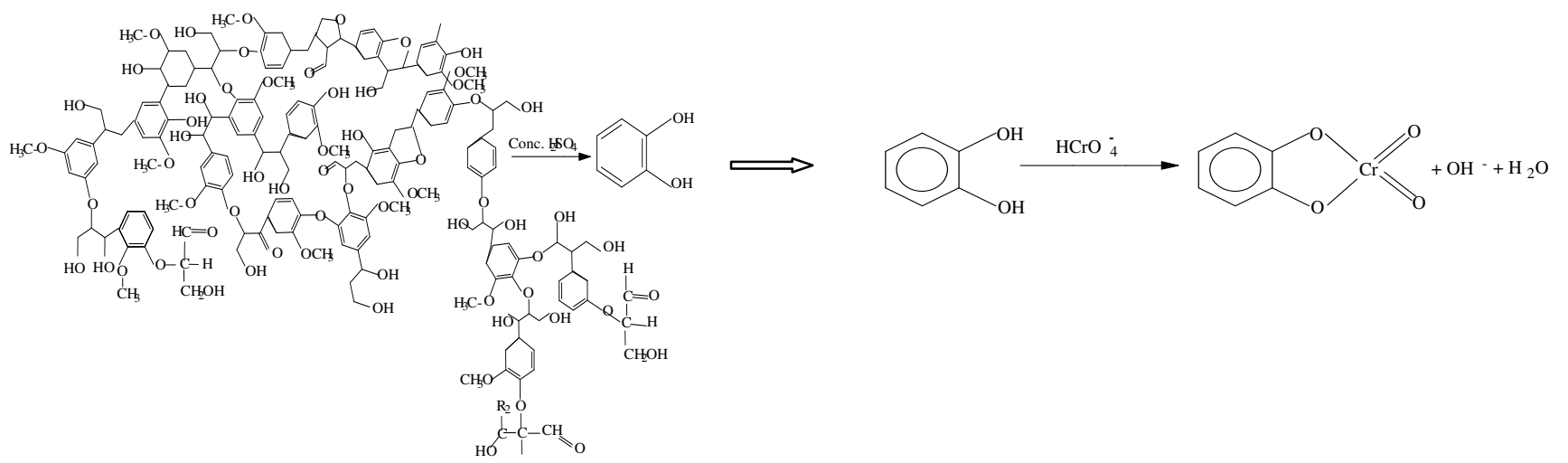

Fig. 18. Plausible adsorption mechanism of $\mathrm{Cr}(\mathrm{VI})$ onto $\mathrm{CPW}$ 


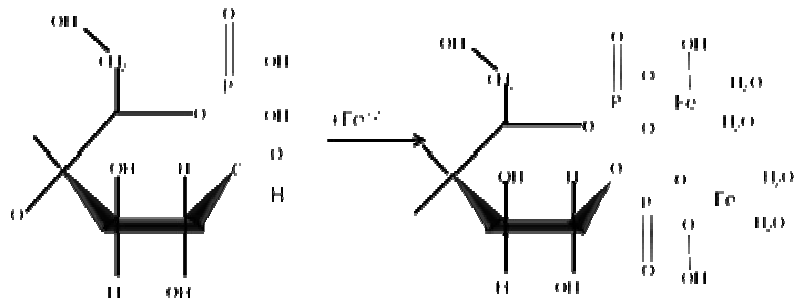

Fig. 19. Plausible adsorption mechanism of $\mathrm{Fe}(\mathrm{II})$ onto PCPW

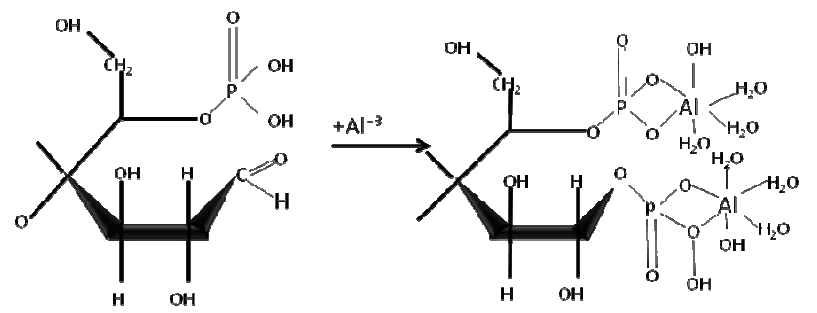

Fig. 20. Plausible adsorption mechanism of Al(III) onto PCPW

\section{CONCLUSION}

An effective adsorbent for the removal of the $\mathrm{Al}(\mathrm{III})$, $\mathrm{Fe}(\mathrm{II})$ and $\mathrm{Cr}(\mathrm{VI})$ has been investigated by making simple chemical modification of the Phragmities waste. The maximum $\mathrm{Al}(\mathrm{III}), \mathrm{Fe}(\mathrm{II})$ and $\mathrm{Cr}(\mathrm{VI})$ uptake capacity of the adsorbent prepared in our laboratory was found to be superior as compared to the previous reports. Thus it can be concluded that chemically modified Phragmities waste can be used for the separation /purification of $\mathrm{Al}(\mathrm{III}), \mathrm{Fe}(\mathrm{II})$ and $\mathrm{Cr}(\mathrm{VI})$ from waste water. The maximum adsorption capacity of $\mathrm{Cr}(\mathrm{VI})$ onto chemically modified Phragmities waste was found $200 \mathrm{mg} / \mathrm{g}$ at the optimum $\mathrm{pH} 1$ and 2, for $\mathrm{Al}(\mathrm{III})$ it was found to be $90.90 \mathrm{mg} / \mathrm{g}$ and $148 \mathrm{mg} / \mathrm{g}$ for CPW and PCPW respectively at $\mathrm{pH} 6$, and for $\mathrm{Fe}(\mathrm{II})$ it was found to be $166.66 \mathrm{mg} / \mathrm{g}$ for CPW and $200 \mathrm{mg} / \mathrm{g}$ PCPW at $\mathrm{pH}$ 2.7. The pseudo-first order, pseudo second order and second order model were used to analyse the kinetic data and it was found that the pseudo-second order model fitted well with the experimental data. Metal recovery after three cycles use of the adsorbents through desorption test shows that maximum recoveries of $\mathrm{Al}(\mathrm{III}), \mathrm{Fe}(\mathrm{II})$ and $\mathrm{Cr}(\mathrm{VI})$ were found to be $82 \%, 91 \%$ and $100 \%$, respectively.

\section{ACKNOWLEDGEMENTS}

This research work was fully supported by University Grant Commission, Nepal under the scheme of Institutional Research Grants.

\section{REFERENCES}

Benefield, L.D., Jadneins, S. and Wend, J.F. 2007. Process chemistry for water and wastewater treatment, Prentice-Hall, Inc, Engle Wood Cliffs, New Jersey. 2(8): 188-195.

Chand, S.A., Aggrawal, V.K. and Kumar, P. 1994. Removal of hexavelent chromium from the wastewater by adsorption. Indian Journal of Environmental Health. 36(3): 151-158.

Ghimire, K.N. 2007. Treatment of arsenic from aquatic environment on to $\mathrm{Fe}$ (III)-loaded orange waste. Spectrum 13: 7-10.

Ghimire, K.N., Inoue, M.K.K. and Miyajima, T. 2002. Effectiveness of phosphorylated orange residue for toxic oxo-anion removal Designed monomers and Polymers, 4, 401-414.

Homagai, P.L., Ghimire, K.N. and Inoue, K. 2010. Adsorption behavior of heavy metals onto chemically modified sugarcane bagasse. Biosource Technology. 101: 2067-2069.

Kumar,U., Bandyopadhyay, M. 2006. Sorption of cadmium from aqueous solution using pretreated rice husk Bioresource Technology ,97, 104-109.

Lal, J. and Sing, D.K.J. 1992. Removal of chromium (VI) from the aqueous solution using waste tea leaves carbon. Water Pollution Control Federation. 47: 243-244.

Mohan, D., Sing, K.P.and Sing, V.P. 2006. Trivalent chromium removal from wastewater using low cost activated carbon derived from agricultural waste material and activated carbon fabric cloth. Journal of Hazardous Materials 135(1/3): 280-295.

Mendham, J., Denny, R.C., Barnes, J.D..,Thomas, .J.K. 2003. Vogel's Text book of quantitative chemical analysis, 6th edition, Pearson Educational Pvt. Ltd., New Delhi, India, 668.

Nasim, K. and Ahmad, M.H. 2001. Water and Waste Water Asia. Journal of Chemical Engineering 84: 95-105.

Sandell. E.B. 1965. Colorimetric determination of trace metal from aquous medium. $3^{\text {rd }}$ Edition, London, Inter science Publishers, Inc. New York.

Sharma, D.C. and Forster, C.F. 1994. A preliminary examination into the adsorption of hexavalent chromium using low-cost adsorbents. Bioresource Technology 47(3): 257-264.

Sud, D., Mahajan, S., Kaur, M.P. 2008. Agricultural waste material as potential adsorbent for sequestering heavy metal ions from aqueous solutions. A Review, Bioresource Technology. 99: 6017-6027. 